\title{
Population Aging and Economic Dynamics in Ukraine: Models of Endogenous Growth Theory and Empirical Estimates of Current Challenges
}

\author{
Valeriy Heyets \\ Director \\ (of Affiliation) \\ State Organization "Institute for \\ Economics and Forecasting, National \\ Academy of Sciences of Ukraine" \\ Kyiv, Ukraine \\ gvm@ief.org.ua
}

\author{
Mariya Skrypnychenko \\ Department of Modeling and \\ Forecasting of Economic Development \\ State Organization "Institute for \\ Economics and Forecasting, National \\ Academy of Sciences of Ukraine" \\ Kyiv, Ukraine \\ skrypnichenko@gmail.com
}

\author{
Svitlana Shumska* \\ Department of Modeling and \\ Forecasting of Economic Development \\ State Organization "Institute for \\ Economics and Forecasting, National \\ Academy of Sciences of Ukraine" \\ Kyiv, Ukraine \\ sv.shumska@gmail.com
}

\begin{abstract}
Among the global problems faced by different countries in the last decade, the article looks at population aging. In the context of assessing the impact of population aging on economic dynamics, the scientific novelty of research is to find a solution to this problem in the plane of conceptual ideas formulated in theoretical models of endogenous growth.

The authors emphasize the necessity of a state policy aimed at supporting "active aging", which will help to activate human capital and economic growth by increasing formal employment of people over 60 and reducing informal employment accordingly. Using the linear regression equations, the hypothesis that there is a positive effect of active aging on economic dynamics and productivity in Ukraine has been statistically confirmed and quantitative estimates of the impact of these factors have been obtained. The authors' calculations show that the positive effects of such policy, in particular, are possible with the increase in health care costs, which depend on the activity and mobility of the retirement age.

Among the challenges, the authors tested the hypothesis of an increase in informal employment and the shadow economy in the absence of government policies aimed at addressing aging. The use of VAR modeling has made it possible to confirm the relationship between real GDP, informal employment and the size of the shadow sector of the Ukrainian economy. The impulse response functions and variance decomposition confirm the negative impact of the growth of informal employment and, accordingly, the shadow economy on the economic dynamics in Ukraine.
\end{abstract}

The practical significance of this study is the application of its results in the development of measures of economic policy and strategy of socio-economic development of Ukraine.

Keywords-population aging, endogenous growth theory, informal labor, regression analysis, VAR model, Ukraine

\section{INTRODUCTION}

In 2019, experts of the World Economic Forum (WEF) among the trends that will determine global development over the next 10 years were again called "population aging" [1]. Such an assessment reflects a large number of interrelated risks that have a negative impact on the economic development of countries with different income levels and indicates the need for a set of measures of economic and social policies aimed at reducing the threats behind aging.
The United Nations projected that, by 2050, the world's population will grow by $40 \%$ and its average age by 7.8 years. Until the year 2100 the world's population will become 11.2 billion and from that 3.2 billion will be at least 60 years old [2]. Compared to the recent past, these indicators show a slowdown in population growth and a significant acceleration in population aging.

For Europe, this problem is more urgent than for other countries in the world. Over the last decades, the mortality rate has increased significantly in the countries of the region and the average life expectancy has increased. At the same time, the overall fertility rate is lower than the population reproduction rate. According to Eurostat forecasts, the demographic revolution will increase the population by 10 million by the middle of the 21 st century, but more than $50 \%$ will be citizens aged over 65 [3]. First of all, the aging of the population leads to a reduction in the workforce and an increase in the workload of disabled people in employment.

For stable economic growth, a modern solution to the global aging problem is considered in three directions, namely through: the introduction of technologies and innovations that increase labor productivity; labor migration; intensification of policies aimed at more efficient use of existing labor resources.

It should be noted that the results of efforts in the first two directions for countries with different levels of economic development due to their different potentials will be different, and in some cases opposite. So, firstly, if developed countries through the introduction of technology and innovation, robotics, increasing labor productivity, can mitigate in the short and medium term, and in the long term it is possible to solve the problem, then economically weak countries do not have such an opportunity in the short term, which over time will only increase the threat of a decline in economic dynamics. Secondly, the intensification of migration processes reduces the severity of the issue for countries with developed economies and high incomes. However, global economic benefits are unevenly distributed between countries of origin of migrants and countries of destination of migrants. For countries receiving migrants, migration usually brings economic growth through an increase in the share of youth in the employment structure, as well as trade, investment and entrepreneurship, especially 
for a stagnant economy with an aging population. While for countries of origin, experts remain concerned that skilled labor migration often causes pure economic damage, in particular, depriving them of national human capital, which reduces their wealth and growth potential [4].

The third area - more efficient use of labor resources can have a positive effect in most countries. For example, we can talk about removing undeclared employment from the shadows, reducing informal activity and about "active aging". The latter does not mean a simple increase in the retirement age, since in most countries it has already been increased, but about the further work of people after retirement. The use of retirees who want to continue to work, who for the most part are skilled workers, will make it possible to more effectively use those with labor resources and accumulated human capital.

\section{THE THEORETICAL BACKGROUND}

The possibility of using internal sources, additional factors and determinants, determined by the subjective behavior of people, the goals of society and the state, to activate economic dynamics, which will ensure long-term growth, is the basis of conceptual ideas forming the theory of endogenous growth.

In the context of finding a solution to the global aging problem, it will be appropriate to recall several theoretical models relating to different periods of the development of endogenous theory, which over time have been confirmed statistically and empirically by the practice of different countries. Firstly, these are models of the endogenous development of technology and population growth. For example, in the model of Michael Kremer, endogenously accumulated knowledge determines growth, and technological progress is an increasing function of the size of the population (the larger the population, therefore, more people make discoveries and implement already implemented ones, and accordingly, knowledge accumulates more quickly, i.e. higher rate of technological progress) [5] In relation to the analysis of "active aging", this means that even with a decreasing rate of population growth, a large number of researchers and inventors of retirement age who do not stop working, but make discoveries or implement them, accelerate scientific and technical progress and, accordingly, promote growth.

Secondly, models of endogenous growth and education. The Robert Lucas model considers the possibility of continuous economic growth based on the accumulation of human capital, which is carried out in a special education sector. Education time is the result of an individual consumer choice, which, maximizing future income, selects the optimal ratio between training time and work time [5]. A feature of the modern approach to learning is the expansion of the time frame of the training itself - from the school bench to the last years of life. The emergence of the concept of "lifelong learning" expands the possibilities of education and, of course, its practical application both for those who need to get primary knowledge and those who change or expand the scope of activity at an advanced age.

Thirdly, it is a model of learning-by-doing. First developed by Kenneth Arrow and further improved by Paul Romer, the model demonstrates the possibility of sustainable growth with a constant growth rate of technological progress, which is a consequence of employee training in the process. The result of this process is assigned by firms as an external effect [5]. The applied aspect of these endogenous models in the context of research on the problem of aging is that for learning in the course of activity - training in action, training in work, in practice - highly skilled workers are required who will transmit the accumulated experience, i.e. there are opportunities for the active work of retirees.

Fourth, it is a model of the impact of economic policy. In most models, the question of the impact of state policy on economic growth is addressed through an analysis of fiscal, monetary, trade policies or the impact of public goods created or redistributed by the state. In the case of productive public services with non-competitive and nonexcluded public goods when consumed, the state is able not only to influence sustainable continuous growth, but also to be the cause and source of constantly supported growth. The external effect of public goods allows us to overcome the decline in marginal productivity and maintain constant sustainable growth. The solution to the model shows the dependence of economic growth on both institutional and behavioral parameters, i.e. growth is endogenous [5]. If we understand the global nature of the aging problem, we cannot do without state national policy, since it must be addressed in a comprehensive manner using measures oriented towards reforming and supporting the labor market, healthcare, social services, and innovative development. An important point is the fact that in the absence of a strategy and policy that ensures economic growth, including responding to the problem of aging, the latter aggravates the threat of stagnation, and idle resources flow into the shadow sector of the economy.

At present, there is a lack of a single point of view on interconnections between the old population and the pace of economic growth. All partly, the problem has become the subject of discussion by experts. Some of them show that aging can hinder economic growth because older people save less. This leads to higher interest rates, lower investment and lower productivity. Other experts, for example, N. Maestas, K. Mullen, and D. Powell, argue that aging can actually increase economic growth if people work longer and save more [6]. Research papers of K. Prettner, R. Lee, and A. Mason show the positive impact of an aging population on economic growth: older people have a propensity to save, and so there are more resources for investment that have a positive effect on economic growth [7-8]. According to investigation N.Nagarajan, A.Teixeira, and S.Silva [9], $70 \%$ of authors of all scientific papers for period 1975-2013, concerning studies of population aging and economic growth, have shown a negative impact of population aging on economic growth, $20 \%$ of authors found no correlation between these indicators, and $10 \%$ of authors stated a positive link between population aging and economic growth.

Many scientists have studied the influence of different characteristics of the employed population (structure, number and quality of workers) on the development of the country's economy [10-11]. Most often, economists consider the impact of population growth on economic growth, without paying due attention to the age structure of the 
population. The transformation of the age structure of the country's population is a more important trend than the change in population size. Each age group is characterized by different traits of economic behavior and, therefore, leads to different economic consequences: young people need investment in education, a working population creates a job offer and makes some savings, and retirees need to receive quality health care and pensions. When the relative share of any age group changes, so does the influence of that group on economic dynamics [12].

\section{THE CASE OF UKRAINE}

\section{A. Regression analysis of the impact of population aging on economic dynamics in Ukraine}

In Ukraine, the rate of population decline is one of the highest among European countries. According to the forecast of the Institute of Demography and Social Research of the NAS of Ukraine, by 2050 the population of Ukraine will decrease to 36.3 million people [13]. The decline and aging of the population in the country already has a negative impact on the size and structure of economically active population, with time only their negative impact on the economy increases and social issues are exacerbated.

Based on the conceptual provisions of theoretical models of endogenous growth, an attempt was made to analyze some effects of population aging on economic growth. For this purpose a regression analysis of the impact of population aging on economic dynamics in Ukraine (GDP, GDP per capita, labor productivity) was performed. The exogenous variable "employment rate of the population aged 60-70 years" was chosen as a proxy-variable of aging.

The basic specification of Models 1-3 is:

$$
y_{t}=a_{0}+a_{1} x_{t}+a_{2} z_{t}+\varepsilon_{t}
$$

where: $y_{t}$ - dependent variable (for Model 1 - the index of changes of real GDP of Ukraine to the previous year; for Model 2 - the index of changes of real GDP of Ukraine per capita to the previous year; for Model 3 - the index of changes of labor productivity to the previous year); $\varepsilon_{t}-$ random errors; $x_{t}$ - employment rate of the population aged 60-70 years. The models also have $a_{0}$-intercept and trend $z_{t}$ as exogenous variables that accumulate the integrated effect of other factors (above all, fixed assets, technologies, etc.).

An important key factor in supporting active aging is increasing the health care costs that affect the health and mobility of the aging population [14]. If modern medicine and science help people live longer, but do not motivate them to be active in life and able to work, then it reduces the ability to work for people of retirement age. Therefore, if people live longer and can remain physically active, then the negative impact of population aging on economic growth will be less [15].

Model 4 estimates the impact of budget expenditures on health care (exogenous variable $h_{t}$ ) on the employment dynamics of the 60-70 age groups $\left(\mathrm{x}_{\mathrm{t}}\right)$ :

$$
x_{t}=a_{0}+a_{1} h_{t}+\varepsilon_{t}
$$

The results of estimation of models 1-4 on the basis of information time series for the period 2000-2017 [16] confirmed the hypothesis of a positive link between the variables of economic dynamics and active aging of the population in Ukraine (Table 1).

\begin{tabular}{|c|c|c|c|c|}
\hline & Model 1 & Model 2 & Model 3 & Model 4 \\
\hline $\begin{array}{l}\begin{array}{r}\text { Dependent } \\
\text { variable }\end{array} \\
\text { Regressor }\end{array}$ & Real GDP & $\begin{array}{l}\text { Real GDP } \\
\text { per capita }\end{array}$ & Productivity & $\begin{array}{c}\text { Employment } \\
\text { rate of the } \\
\text { population } \\
\text { by age group } \\
60-70\end{array}$ \\
\hline $\begin{array}{l}\text { Employment rate } \\
\text { of the population } \\
\text { by age group } 60- \\
70\end{array}$ & $\begin{array}{c}0,015 * * \\
(0,002)\end{array}$ & $\begin{array}{c}0,014 * * \\
(0,004)\end{array}$ & $\begin{array}{c}0,003 * * \\
(0,002)\end{array}$ & - \\
\hline Trend & $\begin{array}{c}0,038 * * \\
(0,002)\end{array}$ & $\begin{array}{c}0,038 * * \\
(0,012)\end{array}$ & $\begin{array}{c}0,015 * * \\
(0,007)\end{array}$ & - \\
\hline $\begin{array}{l}\text { Health budget } \\
\text { expenditures }\end{array}$ & - & - & - & $\begin{array}{c}13,229 * * \\
(2,344)\end{array}$ \\
\hline Constant & - & $\begin{array}{c}0,055 * * \\
(0,022)\end{array}$ & $\begin{array}{c}0,686 * * \\
(0,017) \\
\end{array}$ & $\begin{array}{c}-30,427 * * \\
(10,755)\end{array}$ \\
\hline$R^{2}$ & 0,643 & 0,772 & 0,682 & 0,834 \\
\hline \begin{tabular}{|l|} 
Number of \\
observations
\end{tabular} & 10 & 10 & 10 & 11 \\
\hline
\end{tabular}

TABLE 1. RESULTS OF ECONOMETRIC ESTIMATION

The signs ** correspond to 5\% significance level. The standard errors are given in parentheses under coefficient estimates. (Source: authors' calculations)

Model calculations showed that in response to an increase in the employment rate of the population by age group 60-70 this year by 1\%: real GDP may increase by $0.015 \%$ (Model 1), real GDP per capita - by $0.014 \%$ (Model 2 ), labor productivity - by $0.003 \%$ (Model 3). Due to the increase in healthcare spending by $1 \%$ as a share of GDP, the overall annual effect of increasing the employment rate for the 60-70 age groups may average 13.2\% (Model 4).

Further research in this area should be expanded, as individuals in the aging process tend to change their behavior about the new economic reality, which can have a significant impact on the economy (in particular, the accumulation of savings and the increase in their share of income relative to consumption). Due to the negative impact of demographic change, there is a need to reorganize the social security system, health care and implement government programs to improve the situation on the labor market. Thus, one of the important functions of the state is to ensure the needs of the population for material goods and services, the normative level of which for each country is set in accordance with its socio-economic development (living and working conditions, environment, etc.). Improving quality of life will reduce chronic illnesses, which will increase the length of time workers can be active participants in the labor market. At the level of the state and individual enterprises, a number of measures, primarily aimed at improving working conditions, are needed to increase productivity.

\section{B. Challenges in the absence of policies addressing the problem of aging}

The current structure of the economy, the level of technological development and the lack of free financial resources do not currently provide Ukraine with opportunities for technological breakthroughs and innovations that would significantly increase labor productivity and economic efficiency in the short and medium term. Labor migration also does not solve the 
problem of aging in the country, since flows are in the opposite direction - mainly young people are actively leaving Ukraine to work, which only increases risks, reducing supply on the labor market. Older people and retirees have a low standard of living that makes them seek additional income at home country and, as a rule; they find such work in the shadow sector of the economy.

According to the calculations of the Ministry of Economic Development, the level of the shadow economy in 2018 amounted to $30 \%$ of the official GDP of Ukraine. Although official estimates in recent years have shown a downward trend, this high level also indicates a large number of shadow workers, who are the potential labor force for the official economy.

According to the survey "Undeclared Work Survey in Ukraine" (UUDWS), conducted at the end of 2017, as a direct method of researching the labor market and identifying undeclared employment - about 7 percent of respondents admitted that they had been working without declaration, at the same time, about 46 percent of respondents know someone who works without declaration, and every third respondent believes that at least 50 percent of the population of Ukraine works undeclared [17]. Among the main reasons to work in the shade are difficulties in finding regular work, seasonality of work, generally accepted practice of such work, distrust of government bodies, as well as mutual benefits from the sale or provision of services, or the purchase or receipt of services without declaring. Out of those who worked undeclared $74 \%$ are males and 26 are females; $62 \%$ of undeclared workers live in urban and $38 \%$ live in rural settlements. Most of the "suppliers" of UDW are in the 35-44 years age group (32\%), slightly less in the 45-54 years old group (28\%), 25 34 years old groups represent $23 \%$, the youngest $15-24$ years old are $11 \%$ and above 55 years old represent $8 \%$ [17].

If the main reasons stimulating undeclared work are not removed, the share of older people in the structure of shadow employment will increase significantly in the medium term, as today's workers of the age group 45-54 and above 55 years will significantly strengthen it.

The influence of informal employment on the macroeconomic indicators of the development of Ukraine, as empirical studies show, is quite significant. Econometric estimates of the impact on labor productivity in recent years of the analysis of 2014-2016 witnessed a negative effect: ceteris paribus, with an increase of $1 \%$ in the share of informally employed workers in the total number of employed, labor productivity in the economy decreased by an average of 209 million hryvnas per hour [18]. The main explanation for such empirical results is the impact of growing labor migration, which although it reduces the number of unemployed, it also creates pressure on employers in search of qualified personnel. According to experts, this trend of outflow of workers provokes a decrease in the "quality" of labor resources in the Ukrainian labor market, as employers are forced to hire less competitive workers, including those employed in the informal sector, which reduces overall labor productivity.

One of the most common transmission channels of the influence of informal employment on economic growth is the dynamics and size of the shadow sector in the country.
In the absence of state policy aimed at reducing the influence of factors that support the presence and growth of undeclared employment, a shadow economy grows, which ultimately reduces the growth rate.

The key motivation behind undeclared work is the desire of employers, self-employed persons and employees to obtain economic and institutional benefits. The economic benefits of undeclared activities are associated with the potential gains achieved by evading taxes and social contributions, or saving money by circumventing the occupational safety and health requirements or other social obligations [17].

\section{VAR model for assessing the relationship between} informal employment, the shadow economy and economic dynamics in Ukraine

Population aging is a complex process and its effects on economic dynamics depend on many factors, which in turn have a multidirectional effect. In order to put into practice effective policy instruments, preliminary assessments of their impact are needed. To obtain quantitative estimates of the influence of various factors taking into account their mutual influence allows VAR modeling.

In this study, the VAR model is used to test the hypothesis about the negative impact of informal employment and the shadow economy on economic growth in Ukraine. Its confirmation is the first step in assessing the consequences of the negative scenario of population aging: in the absence of a policy aimed at solving the problem, for example, creating conditions for older people to work in the formal sector of the economy and after they retire, as well as reducing undeclared work by at least part of the population group 55-70 years old, most seniors will increase informal employment and the shadow economy. Therefore, for VAR at this stage, indicators of the dynamics of the growth rates of the official economy, levels of informal employment and the informal sector were chosen. The second step will be scenario forecasts for assessing the impact of changes in different age-old groups on shadow dynamics and economic growth.

The analysis was conducted on the official data of the State Statistics Service of Ukraine [16] and the Ministry of Economy and Trade for the period 1999-2017: $Y$ - change of real GDP of Ukraine (\% per year), SHADOW - level of shadow economy (\% as a share of official GDP), INFORMAL is the level of informal employment (\% as the share of informally employed workers to the total number of employed). EViews 9.0 econometric package was used as the software.

Stationarity variables checked using the KwiatkowskiPhillips-Schmidt-Shin Unit Root Test, which found that the series are stationary in levels. The VAR Lag Order Selection Criteria and Lag Exclusion Tests were used to determine the order of the VAR model (optimal number of lags). Taking into account the length of the time series and the results of VAR Lag Order Selection test, as three of the five criteria (Criteria Hannan-Quinn information criterion (HQ), Schwarz information criterion (SC), and Final prediction error (FPE)) was determined that 2 is the optimal number of lags for the model. Validation of model variables for exogeneity/endogeneity using Grander Causality/Block 
Exogeneity Wald Tests gave grounds for rejecting the assumption that all variables are exogenous, therefore, in the constructed VAR model they are endogenous. Model stability check (all points of characteristic polynomial lie in the middle of a single circle) and analysis of statistical characteristics (Akaike information criterion, Schwarz criterion, Adj. R-squared) at its estimation gave grounds for conclusion about correctness of construction and adequacy of VAR model as a system of three equations (3)-(5):

$Y=-0.820 * Y(-1)-0.597 * Y(-2)+0.254 * I N F O R M A L(-1)$ $1.631 *$ INFORMAL $(-2)-2.419 * \operatorname{SHADOW}(-1)+$ $0.863 * \operatorname{SHADOW}(-2)+86.567$

INFORMAL $=0.047 * Y(-1)+0.012 * Y(-2)+$

$0.991 * I N F O R M A L(-1)-0.151 * I N F O R M A L(-2)+$ $0.171 * S H A D O W(-1)-0.134 * S H A D O W(-2)+2.448$, SHADOW $=0.118 * Y(-1)+0.129 * Y(-2)-$ $0.389 *$ INFORMAL $(-1)+0.792 * I N F O R M A L(-2)+$ $1.183 *$ SHADOW $(-1)-0.492 *$ SHADOW $(-2)+1.344$

An approach based on Cholesky's decomposition was used to construct Impulse Response Functions. The form of the presented graphs (Figures 1-2) indicates the different magnitude of the effects of the shock effect on the real GDP index of the selected indicators.

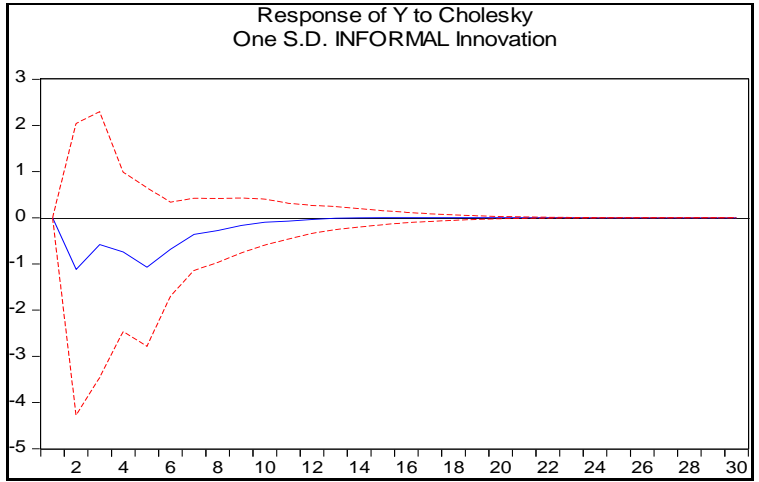

Fig.1. Impulse Response Function of variable $Y$ to shock variable INFORMAL (Source: the author's calculations, output from EViews 9 software).

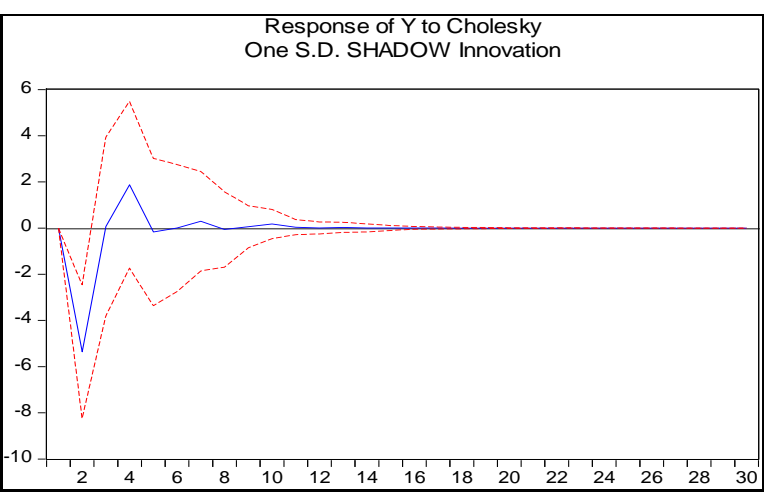

Fig.2. Impulse Response Function of variable $Y$ to shock variable SHADOW. (Source: the author's calculations, output from EViews 9 software).

Although the directions of influence at different intervals are different, they diminish after the 14th period. This indicates that individual shocks/changes in selected indicators (informal employment and shadow economy) have a lasting impact on the economy. In the long run, the graphs coincide with the axis, indicating the stationary of the data series and the stability of the system.

In addition to evaluating the one-time shock on $\mathrm{Y}$, presented in the graphs, a comparative analysis of the accumulated value of shock $Y$ from changes in the variables INFORMAL and SHADOW was also carried out. Calculations (accumulated response of $Y$ to Cholesky (d.f. udjusted) one S.D. innovations) showed that both factors have a negative effect (Figure 3). The cumulative effect of SHADOW is more sharp and strong - already on the second period, the value of the shock from the impulse reached 5.35 std. Deviations. From the 3rd period, the shock $Y$ decreases and stabilizes by 3.02. The influence of INFORMAL, although slower, but on the 5th period negative effects were equal in strength and then influence also reached 5.2, but it was longer in duration than SHADOW.

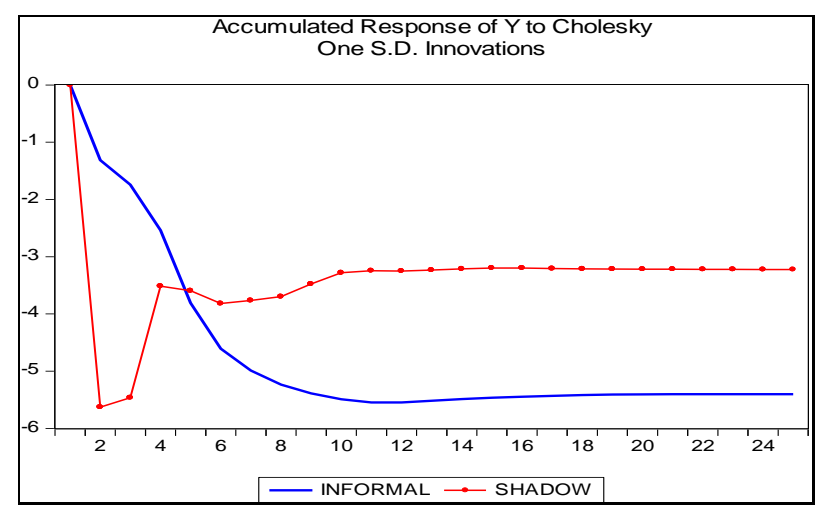

Fig.3. Accumulated value of shock $\mathrm{Y}$ from changes in the variables INFORMAL and SHADOW (Source: the author's calculations, output from EViews 9 software).

It is possible to quantify the effect of the two selected factors on real GDP by calculating the variance decomposition of variables, which allow us to determine how many percent of the change in one variable, is explained by the change in the other. Shown in table 2, the cumulative values of the variance decomposition of $Y$ indicate that from $35-38 \%$ of the variation in GDP is explained by past GDP values (including fundamental factors), and the selected two factors account for up to $65 \%$. The biggest influence on $Y$ is the $S H A D O W$ variable, which contributes up to $60 \%$, which emphasizes the importance for the positive economic dynamics in Ukraine of the need to reduce shadow activity.

TABLE 2. VARIANCE DECOMPOSITION OF VARIABLE REAL GDP OF UKRAINE (Y)

\begin{tabular}{|c|c|c|c|c|}
\hline \multicolumn{5}{|c|}{ Variance Decomposition of Y: } \\
\hline Period & S.E. & $\boldsymbol{Y}$ & INFORMAL & SHADOW \\
\hline 1 & 3.969718 & 100.0000 & 0.000000 & 0.000000 \\
\hline 2 & 6.949130 & 38.04226 & 2.581752 & 59.37599 \\
\hline 3 & 7.025469 & 38.68985 & 3.208460 & 58.10169 \\
\hline 4 & 7.326266 & 36.01579 & 3.974058 & 60.01015 \\
\hline 5 & 7.411057 & 35.33569 & 5.966212 & 58.69810 \\
\hline 6 & 7.447575 & 35.13134 & 6.744792 & 58.12387 \\
\hline & & & & 57.92634 \\
\hline 12 & 7.474988 & 34.93192 & 7.141739 & \\
\hline & & 34.93155 & 7.141856 & 57.92659 \\
\hline 24 & 7.475054 & \multicolumn{5}{|c|}{ (Source: the author's calculations, output from EViews 9 software) }
\end{tabular}


The model shows a strong influence on the dynamics of the real GDP of the shadow economy, which in turn is determined by the level of informal employment, so efforts are aimed at reducing informal employment, and including measures aimed at expanding internal national mobility and shadow reduction will contribute to the revitalization of economic dynamics in Ukraine.

\section{CONCLUSIONS}

Population aging is one of the most important demographic processes that have had long-term effects in many countries around the world. There is no consensus in the contemporary literature regarding the impact of population aging on economic growth. The results of the surveys on the statistical base of Ukraine show the impact of active aging on the economic dynamics, which makes it possible to formulate recommendations on increasing the number of employed and efficient use of the available labor force on the basis of the analysis of existing trends.

The empirical results show that policies to support "active aging" among citizens over the age of 60 contribute to creating conditions for sustainable economic growth, but the positive effects of such measures are possible when increasing health care costs, from which activity and mobility people of the retirement age depends.

In the absence of budgetary and social policies, and in particular measures aimed at making better use of available labor resources, including those aimed at removing them from the shadow economy, there will be an increase in undeclared and informal employment that will increase the shadow economy. The instrumental analysis carried out using the function of impulse responses and variance decomposition confirmed the presence of a significant and lasting negative effect on economic growth in Ukraine an increasing in informal activity that supports the shadow sector of the economy. Policies to reduce "shadow" and create opportunities for continued legal work of retirees can reduce the negative effects of the aging process and improve economic dynamics.

An analysis of theoretical models of endogenous growth with the highlighted of human capital components (based on the role of choice, motivation, and policy) has shown that they can be used to explain the linear and nonlinear links between population aging and economic growth, which will be determined in further research.

\section{REFERENCES}

[1] The Global Risks Report 2019. 14th Edition. World Economic Forum Geneva, 2019. [Online]. Available:

http://www3.weforum.org/docs/WEF_Global_Risks_Report_2019.pdf. Accessed on: May 19, 2019.

[2] A. Guarino, "An aging global population and its economic implications", 2017. [Online]. Available: https://globalriskinsights.com/2017/02/aging-global-populationeconomic-implications/. Accessed on: Aug. 20, 2019.

[3] European Commission. Eurostat. Population and social conditions. [Online]. Available: https://ec.europa.eu/eurostat/publications/statistical-working-papers Accessed on: Jun. 21, 2019.

[4] M. Clemens, "Migration is a Form of Development: The Need for Innovation to Regulate Migration for Mutual Benefit", UN Population Division, Technical Paper, no. 2017/8, New York: United Nations, 2017.

[5] Y. Sharaev, Economic development theory. Moscow, Russia: Publishing house GY VHE, 2006. [in Russian].

[6] N. Maestas, K.Mullen, and D. Powell, "The effect of population aging on economic growth, the labor force and productivity", RAND Working papers, 2016. [Online]. Available: https://www.rand.org/pubs/working_papers/WR1063-1.html. Accessed on: Jul. 12, 2019.

[7] K. Prettner, "Population aging and endogenous economic growth", Journal of Population Economics, vol. 26, no. 2, pp. 811-834, Apr. 2013. [Online]. Available: https://link.springer.com/article/10.1007/s00148-012-0441-9. Accessed on: Jan. 15, 2019.

[8] R. Lee, and A. Mason, "Population Aging and the Generational Economy: A Global Perspective", Northampton, USA: Edward Elgar, 2011, pp. 528-541. [Online]. Available: https://www.ntaccounts.org/doc/repository/Review\%20by\%20Lili\%2 0Vargha.pdf. Accessed on: Jan. 15, 2019.

[9] N.R. Nagarajan, A.C. Teixeira, and S.T. Silva, "The impact of an ageing population on economic growth: an exploratory review of the main mechanisms", Análise Social, vol. 51, no. 218, pp. 4-35. 2016. [Online]. Available:

http://analisesocial.ics.ul.pt/documentos/AS_218_art01.pdf. Accessed on: Apr. 20, 2019.

[10] L. Bettendorf, "Ageing and the conflict of interest between generations", De Economist, no. 159, pp. 257-278, 2011. [Online]. Available: https://link.springer.com/content/pdf/10.1007\%2Fs10645011-9158-5.pdf. Accessed on: Jan. 27, 2019.

[11] S. Aiyar, C. Ebeke, and X. Shao, "The Impact of Workforce Aging on European Productivity”, IMF Working Paper, 2016. [Online] Available: https://www.imf.org/external/pubs/ft/wp/2016/wp 16238.pdf. Accessed on: Jan. 17, 2019.

[12] R. Lee, "Macroeconomics, aging and growth", NBER Working Paper Series, 2016. [Online]. Available: http://www.nber.org/papers/w22310. Accessed on: Feb. 11, 2019.

[13] Ukrainian society: the migration dimension, National report, 2018. [in Ukrainian].[Online]. Available: https://www.idss.org.ua/arhiv/Ukraine_migration.pdf. Accessed on: Apr. 28, 2019.

[14] M. Licchetta, and M. Stelmach, "Fiscal sustainability and public spending on health", 2016. [Online]. Available: http://budgetresponsibility.org.uk/docs/dlm_uploads/HealthFSAP.pdf. Accessed on: Feb. 26, 2019.

[15] A. Zhavoronkov, The ageless generation: how advances in biomedicine will transform the global economy. Palgrave Macmillan, NY, USA: St. Martin's Press, 2013.

[16] Population and migration. [Online]. Available: www.ukrstat.gov.ua. Accessed on: Jan. 15, 2019.

[17] "Undeclared work in Ukraine: nature, scope and measures to tackle it”, ILO Working paper, 2018. [Online]. Available: https://www.ilo.org/wcmsp5/groups/public/---ed_dialogue/--lab_admin/documents/projectdocumentation/wcms_630068.pdf

[18] V. Blyzniuk, and S. Shumska. "Macroeconomic and global effects of expanding the informal segment of labor market: the case of Ukraine", in Proc. $18^{\text {th }}$ International Scientific Conference: Globalization and Its Socio-Economic Consequences, University of Zilina, Rajecke Teplice, Slovak Republic. Part I. - Economic Impact of Migration, pp. 46-53, 2018. Available: URL:

https://ke.uniza.sk/sites/default/files/content_files/i_part_final_0.pdf 